\title{
ИННОВАЦИОННО-ТЕХНОЛОГИЧЕСКАЯ ПОДДЕРЖКА СТРУКТУРНОГО РАЗВИТИЯ ПРЕДПРИЯТИЙ МАШИНОСТРОЕНИЯ КАК НОВЫЙ ИСТОЧНИК ОБНОВЛЕНИЯ
}

\section{INNOVATIVE AND TECHNOLOGICAL SUPPORT FOR THE STRUCTURAL DEVELOPMENT OF MACHINE-BUILDING ENTERPRISES AS A NEW SOURCE OF RENEWAL}

N. Lebedev

Summary. Some issues of innovative and technological support for the structural development of machine-building enterprises are considered. The analysis of the ability of machine-building industry enterprises to develop and produce new high-tech products in competitive markets is carried out.

It is shown that innovative and technological support for the structural development of machine-building enterprises will allow developing and producing new high-tech products in competitive markets, which reveals the importance of using innovative and technological materials, becoming a new source of their renewal.

Keywords: innovations, technologies, machine-building industry, digitalization, structural development, indirect characteristics of equipment, composite materials.

\author{
Лебедев Никита Андреевич \\ Д.э.н., nрофессор, в.н.С., ФГБУН Институт \\ экономики Российской академии наук \\ swonson@bk.ru
}

Аннотация. Рассмотрены отдельные вопросы инновационно-технологической поддержки структурного развития предприятий машиностроения. Проведён анализ возможности предприятий машиностроительной отрасли разрабатывать и производить новую высокотехнологичную продукцию на конкурентных рынках.

Показано, что инновационно-технологическая поддержка структурного развития предприятий машиностроения позволит разрабатывать и производить новую высокотехнологичную продукцию на конкурентных рынках, что обнаруживает важность применения инновационно-технологических материалов, став новым источником их обновления.

Ключевые слова: инновации, технологии, машиностроительная отрасль, цифровизация, структурное развитие, косвенные характеристики оборудования, композитные материалы.
Д оминанта, ключевые концепции, принципиальная возможность структурного развития, вопросы соотношения традиционного и модернизационного, были изначально определены в трудах О. Конта и Г. Спенсера,- считается, что впервые именно они выразили идеи и положения, предварившие внедрение инноваций в социокультурный процесс [1].

В квинтэссенцию модернизации как структурного развития легче вникнуть, учитывая обусловленность категорий модернизации и социальных изменений, перестройки инновационной поддержки развития.

Нельзя не согласиться с рядом авторов, что исходя из социальных тенденций - это переход к стабильности, равновесию [2], а исходя из текущих представлений - это деятельность, присущая передовому, современному, индустриальному обществу [3]. Со своей стороны, инновационно-технологическая поддержка требует длительного поиска предприятиями всё новых и новых проектных решений для упрочения конкурентных преимуществ. И небезрезультативным инструментом их устойчивости во многом выступает поддержка их структурного развития.

В свою очередь, инновационно-технологическая поддержка опирается на использование научных исследований и разработок, обеспечивающих выпуск принципиально новой товарной группы, совершенствования технологических процессов и организации производства для роста её качества.

С этой точки зрения, мотивом к инновационно-технологической поддержке структурного развития предприятий машиностроения может быть стремление к минимизации издержек и к росту прибыли в условиях конкуренции для занятия доминирующего положения на рынке. Однако, предприятиям затруднительно повышать производительность и конкурентоспособность производства без организации инновационной дея- 
тельности, не используя научно-технические средства [4].

Какие же ситуационные сложности, относящиеся к инновационно-технологической поддержке структурного развития, могут стоять перед предприятиями машиностроения? Анализ показывает, что преимущественно, это, уровень технологичности продукции. Следует, однако, отметить, что даже несмотря на то, что в 2021 г. предусмотренные расходы на научные исследования в гражданской области заявлены в сумме более 460 млрд. руб., тем не менее, их объём в ВВП сокращён [5], и к тому же расходы российского бюджета значительно ниже, чем даже в экономически среднеразвитых странах ЕС, что, безусловно, создаёт ситуации вероятного риска при стимулировании инноваций.

В частности, согласно данным Института статистических исследований и экономики знаний НИУ ВШЭ, в 2019 г. технологический объём в преобладающем большинстве экспорт (3,5 млрд. долл.) включал неохраноспособные результаты интеллектуальной деятельности, доминировали инжиниринговые услуги (54,4\% поступлений от экспорта и 45,9\% выплат по импорту технологий), тогда как поступления от экспорта по охраняемым объектам промышленной собственности составляли 1,3\%, при том, что в структуре выплат по импорту аналогичных объектов достиг 27\% [6].

Отчасти, подобная ситуация сложилась по причине проведения Западом санкционной политики, введения карантинных мер и пр., что повлекло снижение уровня сотрудничества, сокращение возможности привлечения в машиностроительную отрасль иностранных инвестиций, что, соответственно, сократило возможности использования доступных технологий.

В этой связи следует отметить, что анализ отдельных макроэкономических показателей демонстрирует следующее: ВВП составил 110046 трлн. руб. [7]. Реальные ежемесячные доходы в годовом выражении составили 35249 тыс. руб. Экспорт машин, оборудования и транспорта составил в 2020 г.7,4\% экспортной структуры страны. Грузооборот всех видов транспорта достиг 5674 млрд. тонно-км.

Росстат оценил объём инвестиций в основной капитал, который достиг 20118 трлн. руб. (в 2019 г.15967 трлн. руб.). Из-за падения спроса наблюдался застойный эффект в автомобилестроении, где в 2019 г., тем не менее, произведено 1,52 млн. легковых автомобилей (снижение в сравнении с 2018 г. составило 2,6\%) [8]. По данным Автостата, грузовых автомобилей в 2020 г. сошло с конвейеров 142 тыс. единиц, (снижение в сравнении с 2019 г. составило 8,7\%).
Тем не менее, предприятия машиностроительной отрасли имеют немалый потенциал технологической поддержки: в 2020 г. возраст 67,8\% оборудования превышал двадцать лет [9], обновление основных фондов составляет 6,9\% [10]. Это показывает, что отрасли остро требуется инновационно-технологическая поддержка структурного развития, что, однако, в текущих условиях трудно преодолимо: прежде всего, необходимо провести цифровизацию металлообрабатывающих станков, что, даст, в частности, нарастить производство деталей для многоприводной техники повышенной проходимости; оптимизировать систему развития персонала и численность сотрудников, поднять товарность продукции, в целом совокупность её потребительских качеств, инновационный уровень. В связи с этим, замена или усовершенствование оборудования позволит предприятиям отрасли, несмотря на капитальные расходы и длительный период окупаемости вложений, усилить, к примеру, надёжность системы обеспеченности запасными частями, сокращать производственные расходы и т.п.

В то же время возникает необходимость внедрения современных принципов и подходов к организации и планированию производства с доминированием концепции быстрорастущих секторов экономики, таких как 3D печати и быстрого создания прототипов, рост индустрии которой неотделим от исследований и разработок в производственном секторе, и поэтому с технологической поддержкой структурного развития предприятий повышается эффект от модернизации оборудования.

При этом, тормозит процесс обновления оборудования одна из перманентных проблем инновационно-технологической поддержки структурного развития, присущих российским предприятиям машиностроения - дефицит финансовых средств, что порождает риск отбора и использования устаревшего неэффективного промышленного оборудования. Критерии отбора: конструктивная эффективность оборудования, чем обусловлена его стоимость. В ряде случаев и фактическую производительность, и соответственно, его стоимость руководителями подразделений занижаются для привлечения приоритетного финансирования, в то время как производителями, наоборот, завышаются. Другой критерий - энергоэффективность оборудования. Предприятиям машиностроения необходимо внедрение технологий, что увеличивает энергоэффективность, снижает зависимость от энергоресурсов, и, соответственно, снижает себестоимость продукции, повышает рентабельность, усиливает финансовое положение, отчего принципиально важно отбирать критерии качественного оборудования. Прежде всего, это косвенные характеристики оборудования, что диктует 
цены реализации продукции. И, конечно же,- -это инвестиционный горизонт; оборудование должно быть производительным, иметь длительный ресурс (10-15 лет), чтобы себя окупить. Оборудование должно быть ликвидным на вторичном рынке, т.е. надёжным, чтобы оно могло быть реализованным за инвестиционным горизонтом. К косвенным характеристикам относят и стоимость владения (обслуживания) - стоимость запасных частей и расходных материалов, которая должна быть сообразной. В свою очередь, технологичное, удобное в обслуживании оборудование не должно быть ненадёжным в эксплуатации.

Оценить как общую эффективность оборудования, так и всего процесса производства, по рекомендации ассоциации эффективного управления производственными активами (ассоциация ЕАM) [11] призвана методика OEE (Overall equipment effectiveness), позволяющая при использовании в планировании производства управлять его жизненным циклом, характеризовать его различные аспекты.

При инновационно-технологической поддержке структурного развития трудностью, не меньшей, чем обновление оборудования или нехватка финансовых средств следует признать нерезультативное построение системы бюджетирования - автоматизацию этого процесса, выбора приемлемого программного продукта, его локализацию на некоторых предприятиях. Это относится, в первую очередь, к крупным государственным предприятиям, где традиционно работает правило - осваивать средства в конце бюджетного года, что эффективность расходов обезличивает, по закупкам образует перерасход средств, а в итоге не отражает потребностей предприятий.

С целью инновационно-технологической поддержки структурного развития, предприятия могут прибегнуть к услугам профессиональных независимых аудиторов, в списке задач которых - проведение совокупного аудита, включающего проверку состояния предприятий согласно критериям по выявлению сильных и слабых сторон, имеющих приоритет для достижения конкурентных преимуществ, определения планов хозяйственной деятельности.

Совокупный аудит как способ проверки финансового и имущественного состояния предприятия и как форма достоверности отчётности может быть проведён специалистами, имеющими соответствующее образование и опыт аудиторской деятельности. Инновационно-технологический аудит включает «оценку инновационного потенциала, среды функционирования и развития, инновационной активности и инновационной позиции предприятия» [12].
При проведении технологического аудита, как принято, выделяют три ведущих этапа. Первый, наиболее важный из них, посвящён обзору используемых аудируемым предприятием технологий и анализ их применения. Второй этап - обзор технологий, более характерных для конкурентов, но не используемых на аудируемом предприятии. В течение третьего этапа соизмеряются применяемые технологии и демонстрируемые технологические стандарты для оценки их относительной эффективности в аспекте их внедрения и использования, для чего используют технологический портфель аудируемого предприятия. Обобщение итогов аудита оформляют в виде акта.

Положительного практического эффекта инновационно-технологической поддержки структурного развития предприятий машиностроения возможно достичь путём фронтального инвестирования в инновационные проекты.

К инновационному производству в машиностроении можно, в частности, отнести разработку на предприятиях методов внедрения обширного сортимента резиновых смесей, взаимодействующих в агрессивной окружающей среде.

На экспериментальной и производственной базе производится обширный сортимент резино-технических смесей и изделий. Производственная структура охватывает изготовление резино-технических вулканизированных изделий с применением прессов с различными параметрами плит, выпуск неформовых изделий червячными машинами. Всё сырьё и материалы соответствует техническим требованиям.

С использованием современной производственной базы выпускается широкий ассортимент грязесъёмников, применяемых в машиностроительном оборудовании для защиты внутренних полостей деталей от внешних загрязнителей, активных химических веществ и т.п. Грязесъёмники массово используют в промышленных отраслях - в нефтяной и газовой промышленности, в строительной технике, на транспорте, а также в различном промышленном оборудовании.

Применение подобных инновационно-технологических материалов и оборудования даёт возможность производства продукции с качественно иными потребительскими характеристиками, что выступает как один из основных признаков, позволяющих отнести материалы к категории инновационных. Большая часть инновационных материалов создают и осваивают на иных эксплуатационных условиях, когда использовать распространённые материалы безрезультатно. Как пример таких инновационных материалов 
можно обозначить композитные материалы, которые применяются в самолетостроении, могут выдержать предельные температуры (около двухсот пятидесяти градусов по Цельсию), фиксируемые на сверхзвуковой скорости.

Использование композитных материалов усиливает конкурентоспособность многих секторов экономики: в аэрокосмической промышленности используют лёгкие высокопрочные металлические сплавы, в системах фильтрации применяются антикоррозийные мембраны, для роста эффективности электротурбин - сверхвысокотемпературные конструкции.

Рынок инновационно-технологических материалов включает полный производственный цикл - начиная от первичной переработки, применяемой для большинства типов натурального сырья, возможностей формирования уникальных характеристик и свойств материалов, до изготовления, апробации и использования изделий, как и утилизации производственных отходов.

Базовыми драйверами рынка останутся инновационно-технологические промышленные отрасли, поддерживающие спрос на композитные материалы, в число которых входят авиакосмическая промышленность, медицинские предприятия, автомобилестроение, приборостроение и радиоэлектроника, где спрос диктуется как конкуренцией и необходимостью отвечать всё более высоким экологическим требованиям, так и построением возможностей в сфере конкуренции на долгосрочный период, разработкой новых перспективных технических образцов.
Какпоказывает анализ, становится важным, что дальнейшее развитие цифровых технологий, сделают процесс создания новых материалов более эффективным. И, прежде всего,- это технологии, с помощью которых создают материалы с заранее заданными свойствами или технологии, моделирующие, например, поведение конструкций из инновационных материалов в течение их жизненного цикла. При этом, активность направлена на включение подходов, подразумевающих применение, с одной стороны, машинного обучения, а, с другой, для имитации и анализа поведения материалов - т.н. искусственного интеллекта. Как итог - снижение сроков на их разработку - срок вывода на рынок новых материалов благодаря цифровизации сократился, как считается, с пятнадцати до пяти лет [13].

Инновационно-технологическая поддержка структурного развития предприятий машиностроения как новый источник обновления позволит разрабатывать и производить новую высокотехнологичную продукцию на конкурентных рынках, что обнаруживает важность применения инновационно-технологических материалов, к которым относятся композитные материалы, т.н. «умные» материалы, металлопорошки сложной формы и получение их с использованием аддитивных технологий [14], и дальнейшее развитие рынка аддитивных технологий будет оставаться значимым фактором.

Подобные инновационно-технологические проекты по созданию новых материалов развиваются активно и не могут не приобрести массовость в достаточно разработанных инновационных программах предприятий машиностроения.

\section{ЛИТЕРАТУРА}

1. Батуренко С.А. Классические классовые теории социальной стратификации: А. Сен-Симон, 0. Конт, Г. Спенсер // Социология.- 2019.- № 2.C. 3-10.

2. Богданов А.В. Проблема соотношения традиции и инновации в трудах зарубежных мыслителей (на примере работ 0. Конта, К. Маркса, Г. Спенсера, М. Вебера) // Известия Саратовского университета. Новая серия. Серия: Социология. Политология. — 2018. — Т. 18. — № 3.— С. 345-348.

3. Ожегов С.И. Толковый словарь русского языка.-М., 1949.

4. Давыдянц Д.Е. Экономика предприятия: производительность, интенсивность, конкурентоспособность, эффективность, их взаимосвязи и пути роста: монография. -М.: Миракль, 2021.

5. 0 федеральном бюджете за 2019 год и плановый период 2020 и 2021 годов [Текст] /Федеральный закон от 29.11.2018 № 459- Ф3; Пояснительная записка к проекту федерального закона «0 федеральном бюджете на 2019 год и плановый период 2020 и 2021 годов» [Текст].

6. issek.hse.ru/news/399520404.html

7. Россия в цифрах. 2020.- - С. 33 .

8. Бутов А.М. Рынок новых легковых автомобилей. ниу ВШЭ. - М., 2020.- С. 3.

9. Богатырёв А. Модернизация российских машиностроительных предприятий: потенциал, проблемы и пути их решения [Текст]. / А. Богатырёв, А. Минаков/ Коммерсант. — № 92 (6572). — С. 2.

10. Износ основных фондов [Электронный ресурс] — Режим доступа: URL: https://zen.yandex.ru/media/obetomnegovoryat/iznos-osnovnyh-fondov-vrossii-bez-emocii-s-ciframi-5d2ca8668da1ce00aed2231d

11. Ассоциации эффективного управления производственными активами [Электронный ресурс] — Режим доступа: URL: https://eam.su/ 
12. Шегурова В.П., Засимова А.В. Аудит инновационной деятельности // Вестник Волжского университета имени В.Н. Татищева. 2018. — Т. 2.— № 1. C. 110-117.

13. Новые материалы в промышленности // Агентство промышленного развития Москвы (ГБУ «АПР»._ М., 2020.

14. Курбанова А.Н. и др. Особенности материалов и технологий аддитивного производства изделий // Чебышевский сборник. 2019.- Т. 20.- № 3 (71). - C. 453-477.

(с) Лебедев Никита Андреевич ( swonson@bk.ru ).

Журнал «Современная наука: актуальные проблемы теории и практики»

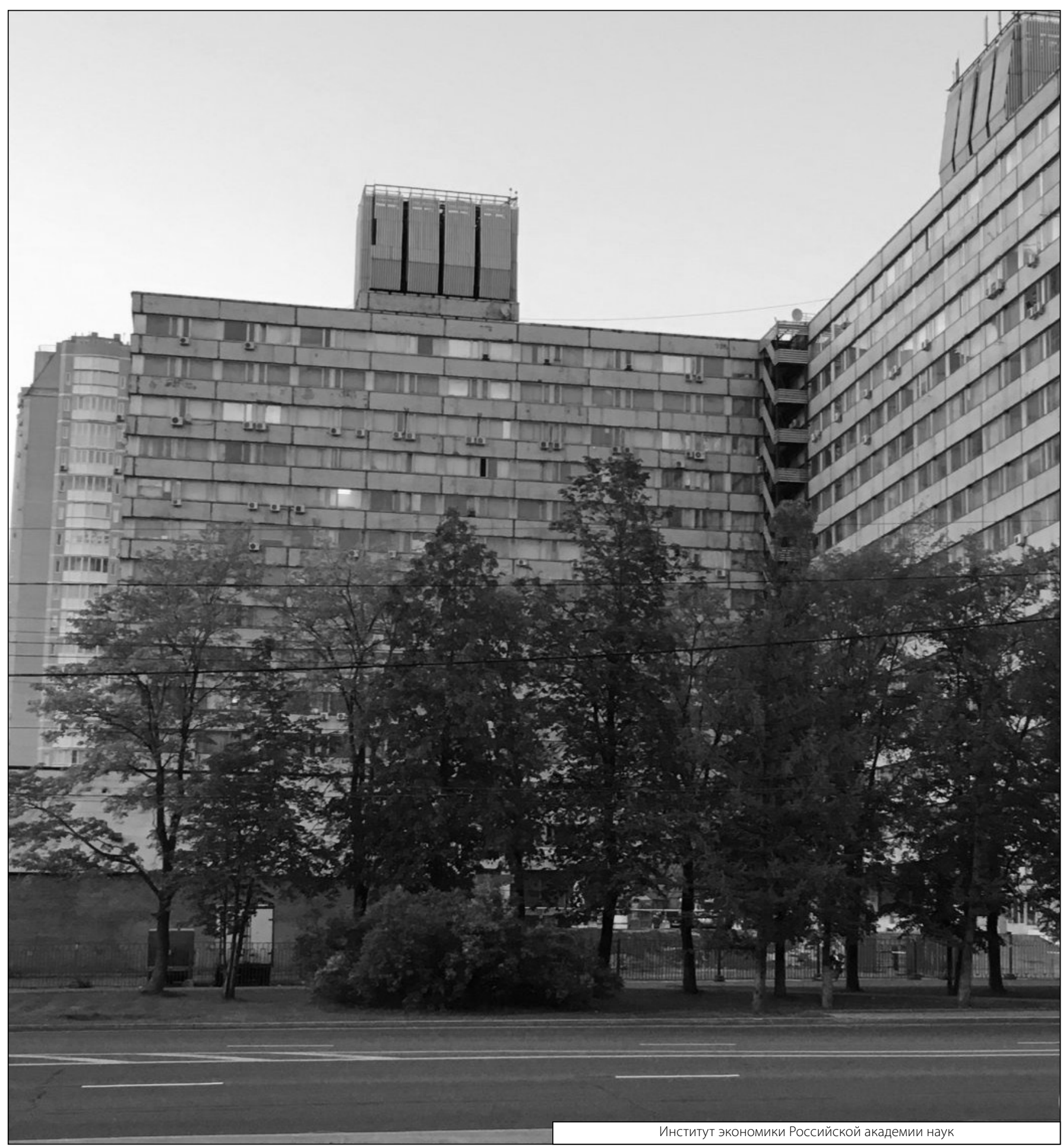

